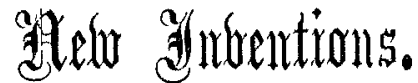

\section{LARYNGEAL AUTO-INSUFFLATOR.}

THE superiority in laryngeal conditions of medication by powders, on account of the more lasting effects of such substances as compared with solutions, coupled with the difficulty of accurately insufflating pulverised bodies into the larynx by individuals unaccustomed to throat work, has led me to devise an instrument (made for me by Messrs. Wood and Son, Manchester) by which powders can be readily blown into the organ by the patient or his friends. The apparatus consists of a straight tube with a receptacle for powder at one extremity and a small hole somewhat like the eye of a catheter at the other. This aperture is to be kept downwards when the tube is introduced and a tiny ivory knob on

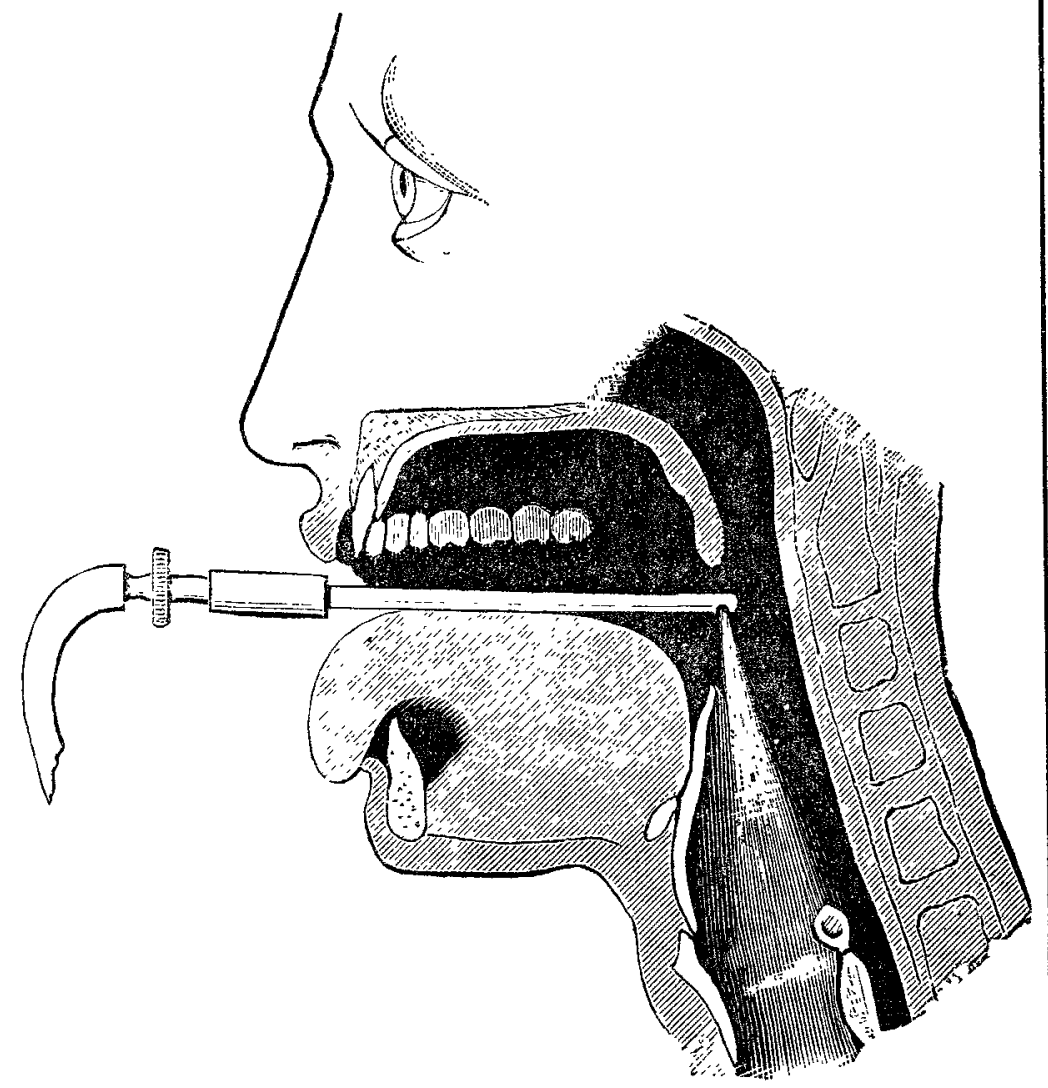

the insufflator indicates its position. A tube and bellows complete the instrument, which should be passed into the mouth, resting on the tongue, until the soft palate is touched, the tongue being protruded. A deep inspiration is then taken and simultaneously the bellows are forcibly compressed, when the powder is partly aspirated and partly blown into the larynx. The advantages of the insufflator appear to be that (1) it can be used by the patient or his friends owing to the abolition of the usual terminal curve, thus obviating irritation of the sensitive parts about the pharynx by the inexperienced manipulator; (2) the end is not liable to be jerked when the powder is insufflated, as occasionally happens in the instrument ordinarily employed; (3) the powder is evenly distributed; and (4) the price is comparatively small $(5 s .6 d$.).

St. Ann's-arcade, Manchester.

E. S. YoNGE, M.D. Edin.

NEW ASEPTIC OPERATION AND DRESSING TRAYS.

HAVING given an extensive trial to the various dressing trays usually sold and to several of $m y$ own design, I have now arrived at the most convenient and useful shape which has been made for me by Messrs. Arnold and Sons, West Smithfield, London. The trays are made in sets of three and all fit into one another to economise space and to keep out dust. They are made of tinned copper and can be boiled, scrnbbed, and generally made aseptic. They serve for boiling instraments in before or after an operation, while they are adapted for carrying the dressings and sponges in a moist condition to an operation. They are equally adapted for private and hospital work. They fit almost every part of the body. To catch liquid at an ordinary laparotomy or operation about the inguinal canals one tray is put between the thighs and jammed well up against the perineum, while the other two are placed close up against the loin and thigh on either side of the patient. Any amount of washing out and slaicing the skin or operation area may be freely indulged in without wetting the tables and blankets. For all operations the trays serve as instrument holders half filled with antiseptic lotion. It will be found very convenient to keep a pair with, say, the usual instruments for curettement
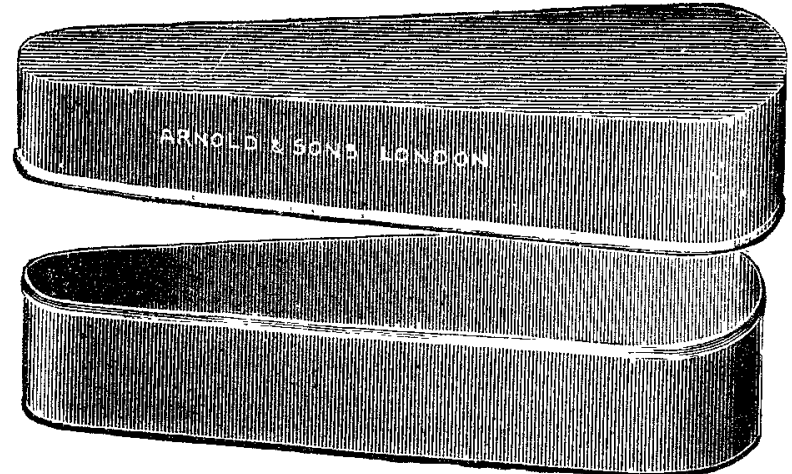

of the uterus always stowed in them-enema, uterine tube, Hegar's dilators ap to 15 , curettes, volsellum, \&c. Two form a dust-proof box and can be kept on a shelf ready for instant use.

T. HopE LwWIS, Surgeon, Auckland Hospital, New Zealand.

\section{A SAFETY WINDOW.CLEANERS' "CHAIR."}

WE give below an illustration of a device for the prevention of accidents from window-cleaning. In our opinion there should be no necessity for such an invention, inasmuch as in the interests of humanity local authorities should have the power, if they do not already possess it, of making it illegal for a person either to sit or stand on a window-sill above the ground floor of a building for the purpose of cleaning a window. Until such necessary laws are made, however, we welcome any device which will prevent or minimise danger to life or limb from this canse. As will be seen from the illustration, two strong pieces of board rest against the frame and brickwork enclosing the frame of the window. These boards are connected together by two

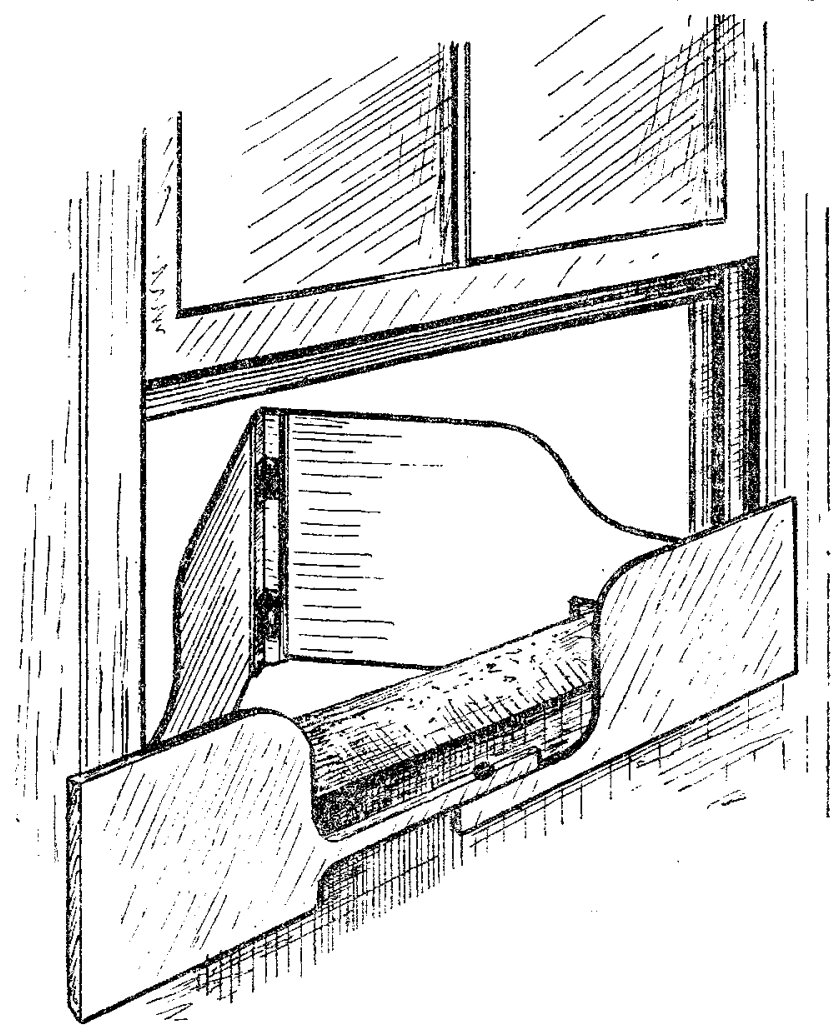

arms of wood which slide one upon the other in order that the boards may be regulated to the width of the window. These arms are fixed together by means of a screw. Hinged to the side of each board facing the street are two other pieces of board which meet at an angle formed by means of a strong. hinge. An immoveable back rest is thus formed for the person cleaning the window, who is consequently enabled with safety to use both hands in the task of cleaning the window, instead of being forced to hold on to the bottom of the frame with one hand. The price of the article is only $4 s$. $6 d$., and communications concerning it should be made to the inventor, Mr. H. Gold, 21, Great Eastern-street, E.C. 